\title{
FUNDO DE DESENVOLVIMENTO AGROPECUÁRIO DE TUPANDI - FUNDAT
}

\author{
Otávio Prado ${ }^{1}$ e Marco Antonio Teixeira ${ }^{2}$
}

RESUMO: Este trabalho apresenta a experiência do Fundo de Desenvolvimento Agropecuário de Tupandi, FUNDAT. Criado em 1993, no pequeno município de Tupandi, pertencente à região metropolitana de Porto Alegre (RS), seu objetivo inicial era romper com a estagnação econômica por que passava o município, promovendo o financiamento de atividades agropecuárias. Como resultado de uma gestão eficiente e inovadora, o FUNDAT conseguiu não só reverter a situação em que se encontrava o município, mas também promover uma melhora nas condições gerais, levando Tupandi a ter hoje uma das melhores qualidade de vida entre os municípios brasileiros, mostrando que soluções simples podem ser muito eficientes quando bem gerenciadas.

PALAVRAS CHAVE: Tupandi, Fundo de Desenvolvimento, Inovação, Transformação, Qualidade de Vida.

ABSTRACT: This paper presents the experience of the Development Fund for Agricultural of Tupandi, FUNDAT. Created in 1993, in the small city of Tupandi, belonging to the metropolitan region of Porto Alegre (RS), his initial goal was to break with the economic stagnation that passed by the council, promoting the financing of agricultural activities. As a result of innovative and efficient management, the FUNDAT reverse not only the economic situation of the council, but also promote a general improvement in the conditions, that led Tupandi to have one of the best quality of life among Brazilian municipalities, showing that simple solutions can be very effective when well managed.

KEYWORDS: Development Fund, Innovation, Transformation, Quality of life.

\footnotetext{
${ }^{1}$ Geólogo e historiador. Mestre e doutorando em Administração Pública e Governo na Escola de Administração de São Paulo da Fundação Getulio Vargas. Pesquisador do CEAPG / FGV.Endereço: Av. Nove de Julho, 2029 - 11º andar Bela Vista - CEP 01313-902 São Paulo - SP.

${ }^{2}$ Doutor em Ciência Política pela Pontifica Universidade Católica de São Paulo. Docente da Escola de Administração de São Paulo da Fundação Getulio Vargas. Pesquisador do CEAPG / FGV. Endereço: Av. Nove de Julho, 2029 - 11º andar Bela Vista - CEP 01313-902 São Paulo - SP.
} 


\section{Introdução}

Tupandi é um pequeno município do estado do Rio Grande do Sul, localizado no extremo sul do Brasil. Com $61 \mathrm{Km}^{2}$ de área, possui uma população de cerca de 3.600 habitantes ${ }^{3}$. Tupandi foi emancipado de Bom Princípio, outro pequeno município da região, em 1988 e hoje faz parte da Região Metropolitana de Porto Alegre, capital do estado. Uma característica interessante do estado é que 64\% dos municípios têm menos de 10 mil habitantes, e de modo geral têm sua principal base de sustentação econômica na atividade agropecuária.

O clima subtropical da região, com temperaturas médias ao longo do ano de $18^{\circ} \mathrm{C}$, não só condicionou as atividades agropecuárias desenvolvidas na região, mas também foi importante para a colonização alemã da região. Em Tupandi, esta presença está marcada profundamente, na cultura com suas festas típicas, na língua falada cotidianamente pela maioria da população, um dialeto franco-alemão, e na importância que a comunidade atribui a valores como disciplina e obediência, aos costumes morais e religiosos e a valorização do ensino fundamental obrigatório.

Alguns indicadores permitem reconhecer nesta região características distintas do restante do país. Os municípios da Região Metropolitana de Porto Alegre possuem um rendimento médio da população economicamente ativa de 884,00 reais, superior em $22 \%$ à média do país ${ }^{4}$, e uma taxa de desemprego de 10\%, pouco menor que as das maiores regiões metropolitanas do Brasil. Em Tupandi os indicadores são ainda melhores: o PIB per capita passou de R\$ 777,00 em 1989 para R\$22.114,00 em 2004. Segundo dados do IBGE do censo de 2000, a expectativa de vida média da população em Tupandi era de 76,6 anos, superando a média brasileira que era de 67,8. O índice de mortalidade infantil em 2006 foi zerado no município, o que é um resultado significativo quando se considera que no Brasil este valor era é de 24,9 para cada mil nascidos vivos. A taxa de analfabetismo era de apenas 4,14\%, enquanto a taxa média brasileira era de 13,3\%. Já no censo populacional de 1991, Tupandi tinha a maior taxa de alfabetização dos chefes de domicílio entre os 4.491 municípios então existentes no Brasil. Por tudo isso, Tupandi possui um IDH-M elevado, de 0.822, superior ao do estado, que é de 0,814 e bem mais alto que a média do Brasil, que é de $0,766 .{ }^{5}$

\footnotetext{
${ }^{3}$ Dados da contagem populacional do IBGE para 2007. Disponível em: http://censos2007.ibge.gov.br/

4 (PNAD, 2004)

${ }^{5}$ Dados do Atlas de Desenvolvimento Humano/PNUD (2000)
} 


\section{Contextualização}

Para entender a importância do FUNDAT nas transformações ocorridas em Tupandi, é necessário entender a situação da região antes de sua criação. Como ocorre em quase toda a região, a economia de Tupandi esteve fundamentada na agricultura, que se caracteriza pela presença de minifúndios de produção familiar.

Logo após sua emancipação em 1988 e a despeito da existência de alguns excelentes indicadores sociais, Tupandi apresentava problemas que inviabilizavam o seu crescimento econômico. Um deles era a estagnação da produção agro-pecuária. Outros problemas de infra-estrutura, como a ausência de asfalto ou rede telefônica no município impediam não só o desenvolvimento das atividades agropecuárias, mas também o estabelecimento de indústrias na região, que poderiam diversificar as atividades econômicas locais. Algumas regiões de Tupandi, como o Morro da Manteiga, que hoje está tomado por aviários extremamente produtivos, eram na época regiões de muita pobreza.

Neste cenário, a população não tinha opções de emprego em Tupandi, além das raras oportunidades de trabalho nas propriedades rurais mais produtivas. Como conseqüência desta estagnação geral do município, verificava-se um êxodo da população em idade produtiva, seja para trabalhar nas indústrias de calçados dos municípios próximos, ou mais freqüentemente migrando para localidades mais distantes, como Novo Hamburgo, Caxias do Sul e Porto Alegre. Para a população mais jovem, não havia qualquer perspectiva de crescimento em Tupandi. Estes partiam do município em busca de emprego ou mesmo da continuidade dos seus estudos, já que não havia ensino superior na região. Mas como nem todos que partiam eram bem-sucedidos, muitos acabavam morando nas periferias das grandes cidades e vivendo sem qualquer conforto ou esperança de melhora de vida.

Havia na época cerca de 500 pequenas propriedades rurais em Tupandi. Parte do problema advinha da falta de incentivo ou conhecimento, por parte dos produtores, de formas mais racionais e efetivas de produção, já que estes tendiam a adotar as técnicas e os processos produtivos convencionais aprendidos e ensinados pelos seus antepassados. A questão a ser enfrentada era como integrar estes pequenos produtores familiares em um contexto econômico moderno, caracterizado pela produção em grande escala, com infra-estrutura moderna, tecnologia e qualidade e de forma integrada com as grandes empresas integradoras que começavam a atuar na região. Mesmo que estas em geral forneçam assistência técnica, acesso a matérias-primas e 
colocação da produção, era imprescindível que houvesse um apoio por parte do município para que estes pequenos produtores conseguissem viabilizar suas propriedades nesta nova conjuntura.

\section{O FUNDAT}

José Hilário Jungues, prefeito de Bom Princípio à época de emancipação de Tupandi e futuro prefeito de Tupandi era um destes produtores da comunidade. Como produtor rural, ele aproveitou a experiência obtida em uma viagem de estudo para a Alemanha, patrocinada por uma das organizações cívicas de intercâmbio entre Brasil e Alemanha atuante na região, para iniciar a criação de frangos em sistema integrado em 1984, quando se abriu um nicho para exportação deste tipo de produto. Imaginando ser viável ampliar este tipo de produção para todo o município, o prefeito se dispôs a investir em um projeto que permitisse aos produtores locais se inserirem também nesta atividade. Para isso, procurou entender como funcionava o sistema integrado, visitando os estados de Santa Catarina e Paraná como prefeito eleito na companhia do seu futuro secretário de Agricultura, já que nestes estados este tipo de produção já estava mais consolidado.

Com a experiência obtida na viagem de observação e pesquisa, chegaram a conclusão que este modelo poderia ser adotado nas pequenas propriedades de Tupandi, em especial na promoção da avicultura, suinocultura, fruticultura e produção de leite tipo B. O problema a ser enfrentado não era tanto a viabilidade do projeto, mas garantir que o pequeno produtor rural conseguisse os recursos econômicos iniciais para viabilizar a produção, sem que dependessem de financiamento bancário, o que era praticamente impossível para os produtores naquele momento. Ao mesmo tempo, a prefeitura tinha poucos recursos para investimento, sendo que o orçamento total disponível na época era de apenas R\$60.000 por mês.

No início da gestão municipal (1993-96), o modelo de financiamento do sistema de produção foi discutido na Câmara Municipal, tornando o assunto público em todo o município e envolvendo toda a comunidade. Após três meses de discussões, foi criada em 31 de março de 1993 a Lei $n^{\circ}$ 154/93, instituindo o Fundo de Desenvolvimento Agrícola de Tupandi, ou FUNDAT. A lei tinha por princípio apoiar e incentivar as atividades agropecuárias do município, estabelecendo uma espécie de acordo entre prefeitura e colonos no qual a Prefeitura subsidiaria os produtores, enquanto esses se comprometiam a emitir nota fiscal de todas as transações efetivadas. 
Em 1996, a secretária de administração, Liane Noeli Schoffen, e o secretário da agricultura e meio ambiente, Walmor Sicorra, declararam ${ }^{6}$ :

Pela lei do FUNDAT a Prefeitura Municipal subsidiava 100\% do custo da terraplanagem, cortina lateral e do telhado dos aviários, além do acesso aos novos empreendimentos, formado por galpões padrão de 100x12 m. Para a atividade de suinocultura o FUNDAT subsidiava 100\% do custo das telhas, brita e areia necessários a obra, formado por galpões padrão de $60 \times 9 \mathrm{~m}$. Para a atividade de bovinocultura de leite o FUNDAT subsidiava 100\% dos custos das 3500 telhas de barro, 50 sacas de cimento e 4000 tijolos de seis furos.

(...)

$\mathrm{Na}$ evolução do programa houve a necessidade de diversificar o foco dos investimentos em novas alternativas de produção primária. Surgiu o incentivo a citricultura onde o município subsidia até hoje $40 \%$ do custo das mudas. Além de subsidiar 50\% do transporte da produção até a indústria, 100\% do custo do transporte de calcário até as propriedades e auxílio de 50\% do transporte de biofertilizantes. Já na silvicultura, representada por plantações de eucalipto e acácia negra, o FUNDAT tem subsidiado 50\% do custo das mudas.

Uma dificuldade inicial do programa foi convencer o agricultor a abandonar os antigos métodos de produção primária a que estavam acostumados e investir em desenvolvimento tecnológico para tornar suas terras rentáveis. Embora muitos agricultores da região plantassem apenas para sua sobrevivência, isso significava para eles uma vida estável e uma renda fixa, mesmo que pouca. Convencê-los a investir era uma tarefa árdua, já que a construção de um aviário na época implicava custos de até $\mathrm{R} \$ 45.000$ de investimento, além dos benefícios oferecidos pela prefeitura. E esses recursos deveriam ser financiados pelo produtor, que geralmente comprometia tudo o que possuía como garantia do empréstimo fornecido pelo sistema bancário. Em grande parte estes financiamentos foram realizados pelo Banco do Brasil, com uma providencial ajuda do prefeito que, como pessoa física, se prontificou a ser avalista dos empréstimos de muitos produtores. Em 1993, apenas oito produtores se dispuseram a participar do FUNDAT. É interessante notar que todos eles ainda estão no ramo, sendo que a maioria até já expandiu e diversificou sua produção, investindo em citricultura, suinocultura e gado leiteiro.

${ }^{6}$ Inserir referência texto do Klering. 


\section{Características do FUNDAT}

Em sua lei de criação, o FUNDAT não explicita o objetivo central do programa, embora haja um consenso de que seja o de tornar produtivas as propriedades rurais do município. Já seus objetivos secundários são:

- Fixar o homem no campo;

- Criar expectativa de melhoria da qualidade de vida da agropecuária;

- Viabilizar economicamente a pequena propriedade rural;

- Absorver a mão-de-obra familiar disponível;

- Aumentar a arrecadação de ICMS;

- Criar mão-de-obra especializada.

O desenvolvimento das ações, regulamentadas pela Lei Municipal $n^{0}$ 154/93, obedecem as seguintes etapas: Os proprietários se inscrevem na prefeitura e a Secretaria Municipal de Agricultura analisa o pedido, que depois de aprovado é cadastrado e fica disponível para consulta pública. O beneficiário assina então um “termo de compromisso", em que se compromete a cumprir as determinações do programa. Nos primeiros anos de existência os produtores rurais recebiam me média $\mathrm{R} \$ 2.200,00$ de incentivo para a construção de galpões, na forma de serviços e materiais, além da parcela que cada um investia em suas propriedades.

Ao mesmo tempo, a prefeitura promovia cursos profissionalizantes e palestras gratuitas aos interessados, assim como realizava reuniões periódicas para discussão conjunta dos eventuais problemas enfrentados pelos beneficiados, buscando soluções conjuntas. O grande objetivo era que nenhum dos beneficiários falisse, o que poderia inviabilizar o programa, já que a prefeitura não tinha muitos recursos e precisa direcionar parte deles para setores essenciais como a saúde e a educação. Como observa José Hilário Jungues:

“Em comum acordo, as secretarias municipais, junto com o executivo municipal, canalizaram todos os recursos municipais para o programa FUNDAT, mantendo somente os serviços essenciais nas outras secretarias, possibilitando o pleno desenvolvimento do projeto.” 
Dessa forma a prefeitura conseguiu financiar o projeto apenas com recursos próprios. Mesmo tendo havido uma dificuldade financeira em 1994, quando o número de propriedades beneficiadas chegava a 198, o retorno do ICMS resultante do aumento da atividade econômica do município possibilitou não só sua continuidade, como também permitiu a diversificação dos investimentos públicos em outros setores, beneficiando o município como um todo.

\section{Resultados Obtidos}

Analisando o programa a partir dos seus seis objetivos principais: melhoria na qualidade de vida dos cidadãos; Fixação do homem no campo; Viabilização da propriedade rural; Absorção da mão-de-obra familiar disponível; Criação de mão-de-obra especializada e aumento na arrecadação de ICMS, pode-se considerar que o programa obteve um grande sucesso.

A qualidade de vida dos cidadãos foi alcançada com relativo êxito. Em pesquisa de campo realizada em 2007, foi possível constatar que existia uma real satisfação da população com os resultados diretos e indiretos alcançados pelo programa. Isso se nota não só pela grande popularidade da administração junto à população, mas também pelas inúmeras melhorias públicas alcançadas, em especial nas refletidas pelos excelentes indicadores sociais de Tupandi. O êxito do FUNDAT possibilitou um aumento de arrecadação substancial, que pode ser repassado para ações nas áreas de educação, saúde, infra-estrutura e saneamento básico. O aumento da arrecadação do ICMS, que cresceu 521\% entre 1993 e 2007, fruto da implantação do FUNDAT, teve uma grande parcela neste sucesso.

Como exemplos da melhoria da qualidade de vida da população em relação a 1993, pode- se observar os seguintes serviços supridos pela prefeitura: disponibilização de transporte escolar, ensino básico e fundamental para toda população, merenda escolar de qualidade, atividades de cultura e turismo, construção de um centro de eventos, realização de atividades de lazer e desporto, construção de quadras poliesportivas em cada localidade, subsídios para perfuração de poços artesianos, iluminação pública em toda cidade, pavimentação de vias, construção de calçadas, extensão da rede elétrica a todo município e coleta de lixo.

Em relação a fixação do homem no campo, pode-se observar uma grande mudança nos padrões observados anteriormente. Como foi dito anteriormente, Tupandi sofria com um grande êxodo de jovens, que saiam do campo em busca de melhores oportunidades nas grandes cidades. A perspectiva de trabalho no estagnado setor agropecuário não trazia nenhum incentivo a 
permanência deste contingente de trabalhadores potenciais em Tupandi. A agricultura familiar não propiciava perspectivas animadoras.

Como parte do incentivo à permanência destes jovens no campo, a prefeitura passou a exigir, como contrapartida à participação no FUNDAT, que houvesse a participação dos filhos dos produtores nas propriedades beneficiadas. Por outro lado, o próprio sucesso do programa foi responsável pela renovação do interesse destes jovens no retorno a Tupandi. Não só as propriedades estavam se tornando produtivas, mas também surgiam novas oportunidades de trabalho nas indústrias e no comércio que se instalava no município. Se a oportunidade era incerta nas outras cidades, em Tupandi a situação começava e ficar atraente, o que acabou ocasionando um fluxo inverso, fazendo com que nos últimos anos o município tenha se tornado um pólo de atração. Mesmo que o objetivo inicial tenha sido de fixar o jovem no campo, a diversidade de atividades produtivas acabou proporcionando um resultado mais amplo do que o pensado inicialmente.

Com os resultados do FUNDAT, a propriedade rural em Tupandi pode ser viabilizada economicamente. Como exemplo do sucesso do programa, se em 1993 Tupandi produzia 660.000 cabeças, em 2005 este valor chegou a 21.170.000 cabeças de frango, correspondendo a um aumento de 3.200\% na produção total. A associação dos produtores com o município e as empresas integradoras de produção de aves, como Avipal e Frango Sul/Doux, permitiu também que Tupandi se inserisse no mercado global, com grande parte de sua produção direcionada ao mercado externo.

Se a absorção da mão-de-obra familiar disponível também alcançou êxito, já que existe uma grande demanda de mão de obra no município e um incentivo para que as propriedades familiares sejam inseridas ao sistema integrado de produção, a criação de mão-de-obra especializada para o trabalho agrícola ainda é incipiente em Tupandi. Parte do treinamento necessário à produção é repassado aos produtores pelos técnicos da empresas integradoras, pela Secretaria Estadual da Agricultura e pela Emater/RS, que possui um escritório em Tupandi. Apesar disso, ainda falta uma maior profissionalização dos produtores e dos seus empregados, que poderia ser suprida com a criação de uma escola técnica no município ou pelo maior incentivo a que os jovens cursem uma faculdade de veterinária, agronomia ou engenharia ambiental/agrônoma em outras localidades. 
Finalmente, pode-se considerar que o objetivo do programa de promover o aumento do ICMS foi o responsável por grande parte do êxito do FUNDAT. Este sucesso se reflete de forma no próprio aumento da arrecadação municipal, que cresceu quase 10 vezes nos últimos 12 anos, passando de cerca de 1.144.000,00 em 1995 para cerca de 10.285.000,00 em 2007. Com isso o município passou da $375^{\circ}$ colocação em 1995 para a $102^{\circ}$ posição no estado do Rio Grande do Sul em valores de produção.

Apesar da grande participação do ICMS no aumento da arrecadação municipal, o dinamismo econômico proporcionado pelos resultados diretos e indiretos do FUNDAT também teve seu papel no aumento de renda e de investimentos públicos no município. O aumento da arrecadação gerou um círculo virtuoso na economia local, que se reflete em todos os setores produtivos. O aumento da atividade econômica proporcionou um aumento de renda que aumentou a demanda agregada do município, criando uma expansão da oferta para atendê-la.

Como resultado, surgiram não só novas atividades comerciais e de serviço no município, mas também se instalaram indústrias de base, como por exemplo fábricas de tijolo, telhas e pré moldados. Ao mesmo tempo, o incentivo à instalação de indústrias no município criou uma maior diversificação econômica em Tupandi, que fez com que o valor adicionado pela indústria no Produto Interno Bruto em 2004 superasse o valor adicionado na agropecuária em 25\%7.

\section{Conclusões}

A experiência do FUNDAT de Tupandi mostra que não foi preciso criar um programa complexo para resolver os problemas do município, que são comuns a vários outros municípios do Brasil.

Fatores como o comprometimento do pagamento das obrigações legais, como é o caso do ICMS, associados a uma estratégia de participação dos beneficiários que conta com a participação de toda a comunidade, a credibilidade pública advinda de uma gestão correta e imparcial na disseminação dos benefícios por toda comunidade, o planejamento e execução do programa em estrito cumprimento das metas acordadas pelo poder público com participação da comunidade, a visão de modernidade que ousou romper os paradigmas de produção locais, o esforço por proporcionar viabilidade técnica e sustentação econômica dos produtores, garantindo a auto-

\footnotetext{
${ }^{7}$ Dados do IBGE, disponíveis em: http://www.ibge.gov.br/cidadesat/topwindow.htm?1
} 
sustentação do programa e sua grande abrangência mostraram ser fatores fundamentais para o sucesso do FUNDAT.

Em conseqüência disso, seus resultados podem ser facilmente comprovados não só pela evolução positiva dos indicadores quantitativos sócio-econômicos do município, mas principalmente pelo aumento da qualidade de vida da população, refletido em sua população a todos que tem oportunidade de conhecer Tupandi.

Evidentemente nem tudo ainda é perfeito em Tupandi, mas a constatação de que o caminho trilhado parece estar sendo correto é uma boa indicação de que os acertos compensam plenamente os eventuais problemas ainda não solucionados.

\section{Referências Bibliográficas}

Klering, Luis Roque. A experiência pública inovadora do Funde de Desenvolvimento Agropecuário de Tupandi, in: Spink, Peter; Clemente, Roberta [org.]. 20 Experiências de Gestão Pública e Cidadania - Ciclo de Premiação 1996. Programa Gestão Pública e Cidadania, 1996.

Souza, Franciele da Silva Cavalcante; Nascimento, Eros Phillipe Costa Claro do. Tupandi. Relatório final do projeto Conexão Local. Não publicado. São Paulo, 2007.

Steffen, Alex. Nada é Impossível - Vida e Obra de José Hilário Junges, Author, Tupandi: Rio Grande do Sul, 2006.

Steffen, Alex; Konzen, Vicente S.J. Sob a Luz do Céu. Author, Tupandi: Rio Grande do Sul, 2007.

Artigo recebido em: 20/10/2006 e aceito em 02/02/2007. 